The University of Maine

DigitalCommons@UMaine

Vocal Popular Sheet Music Collection

Public domain (may be downloaded in full)

1905

\title{
Every Cloud Has Silver Lining
}

H Engelmann

Composer

Harry M Kramer

Lyricist

Follow this and additional works at: https://digitalcommons.library.umaine.edu/mmb-vp

\section{Recommended Citation}

Engelmann, H and Kramer, Harry M, "Every Cloud Has Silver Lining" (1905). Vocal Popular Sheet Music Collection. Score 2483.

https://digitalcommons.library.umaine.edu/mmb-vp/2483

This Book is brought to you for free and open access by DigitalCommons@UMaine. It has been accepted for inclusion in Vocal Popular Sheet Music Collection by an authorized administrator of DigitalCommons@UMaine. For more information, please contact um.library.technical.services@maine.edu. 


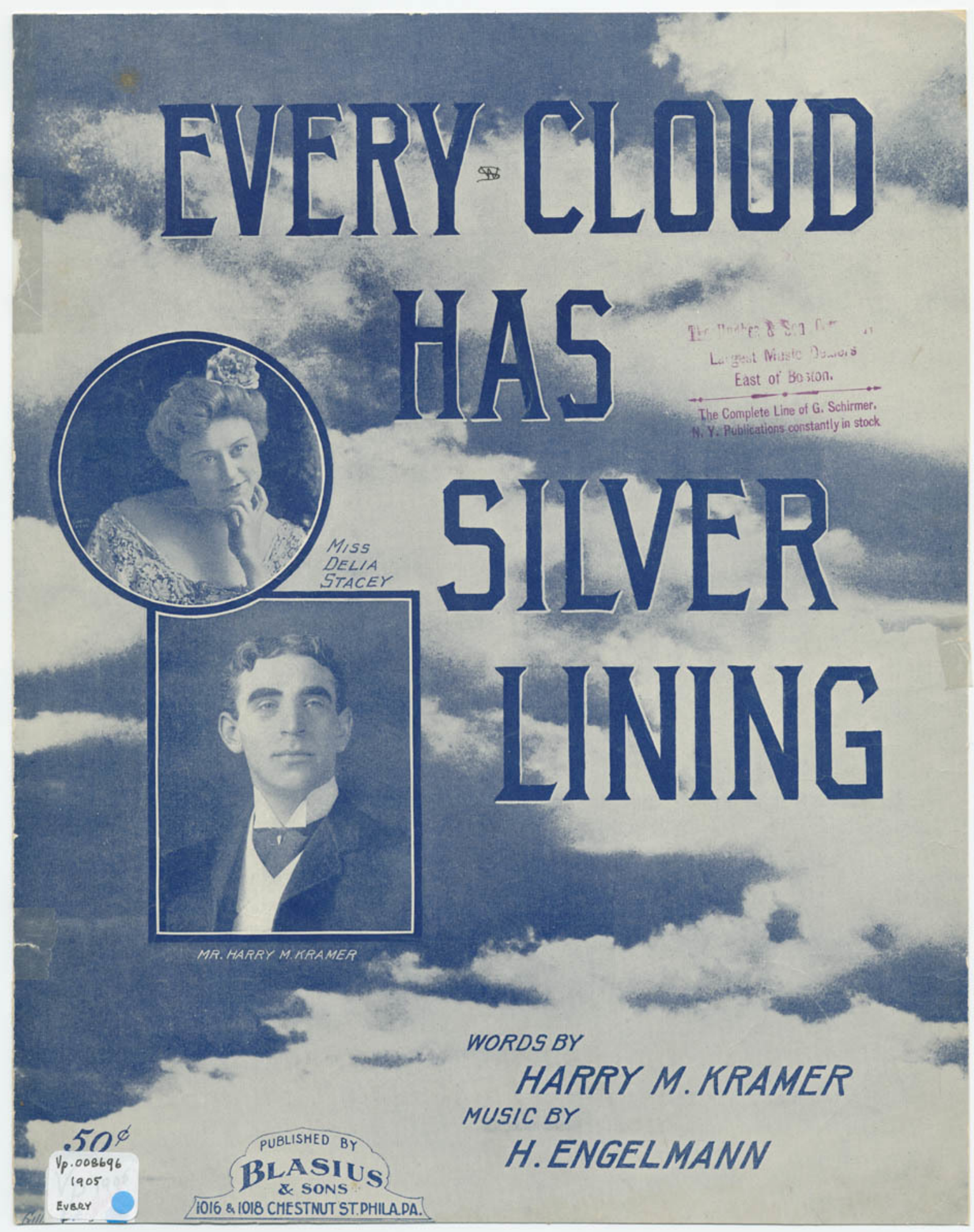




\section{EVERY CLOUD HAS SILVER LINING.}

Words by HARRY M. KRAMER.

Music by H. ENGELMANN.
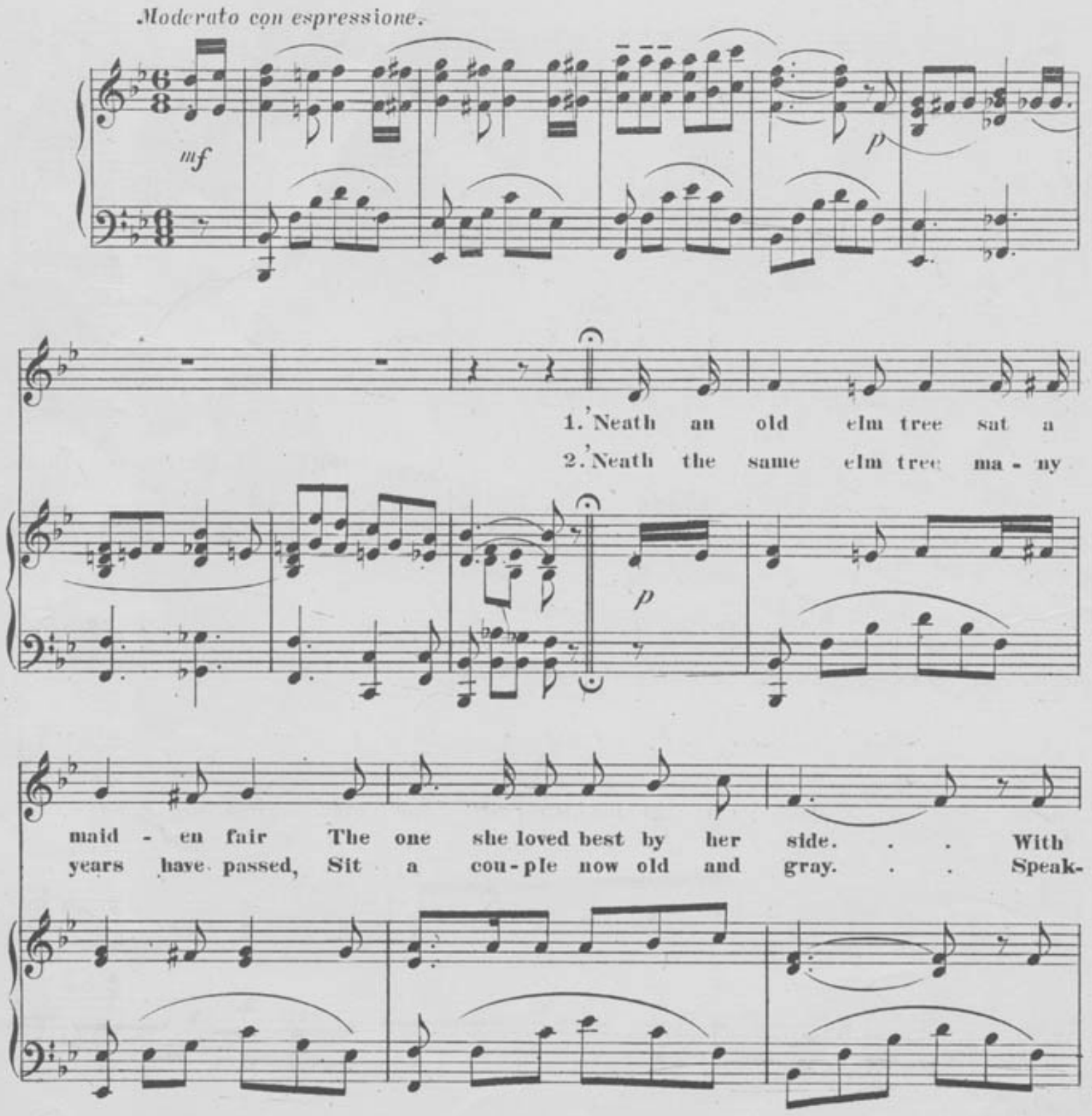

Copyright MCMV by Blasiax \& Son.

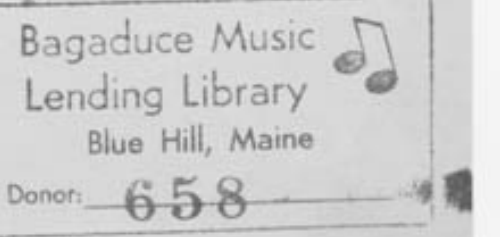


4
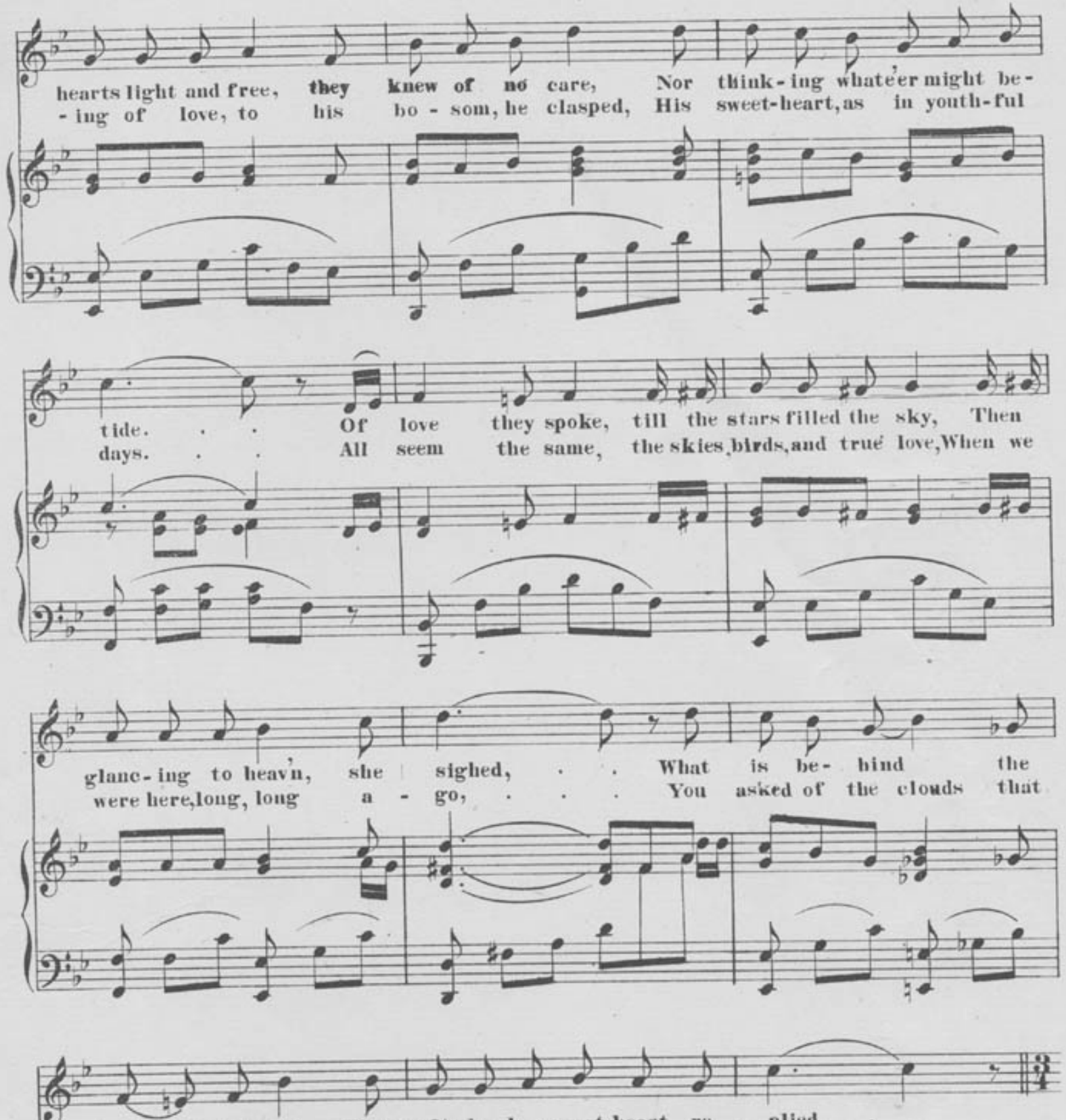

clonds that roll by? Then soft-ly, her sweet-heart re - plied

roll - a-bove, I told you, in nords sweet and

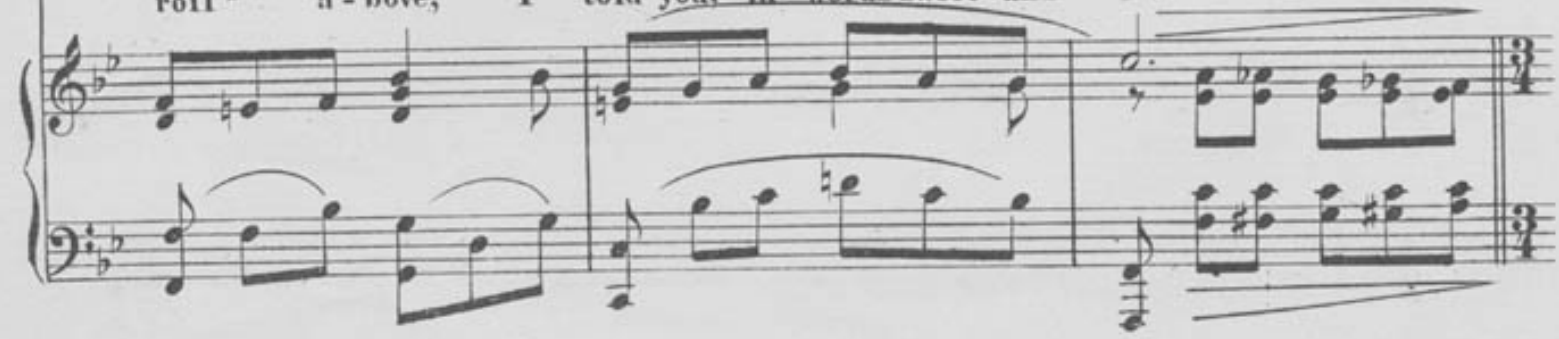

Evory elwat se. 
CHORUS. Andante non troppo.

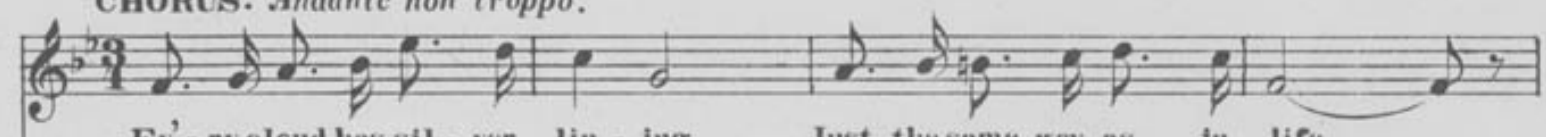

Ev' - rycloud has sil - ver lin - ing, Just thesame way as in life,
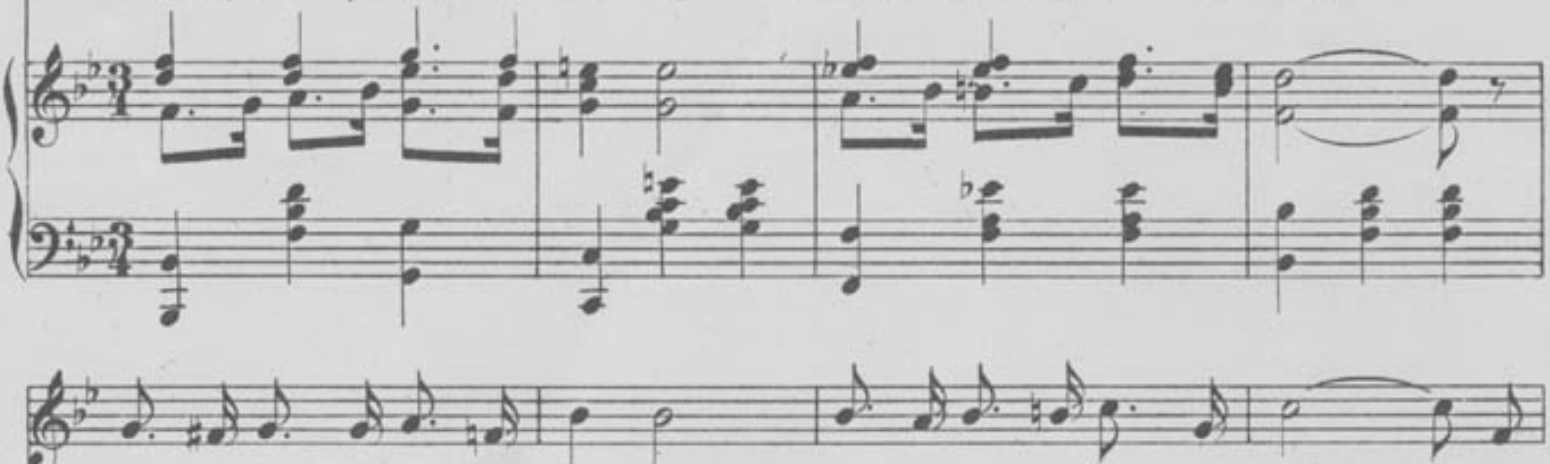

Tell me, dear, why are you pin-ing? Joy will al-ways fol - low strife. When
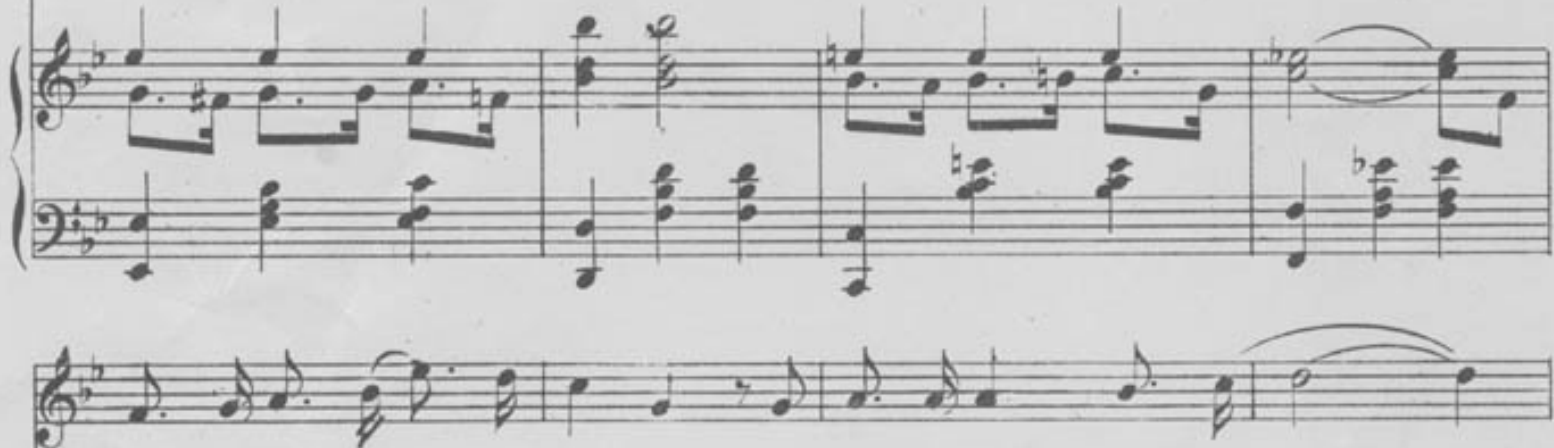

gray, with our days. de - elin-ling We will nev-er know of gloom,
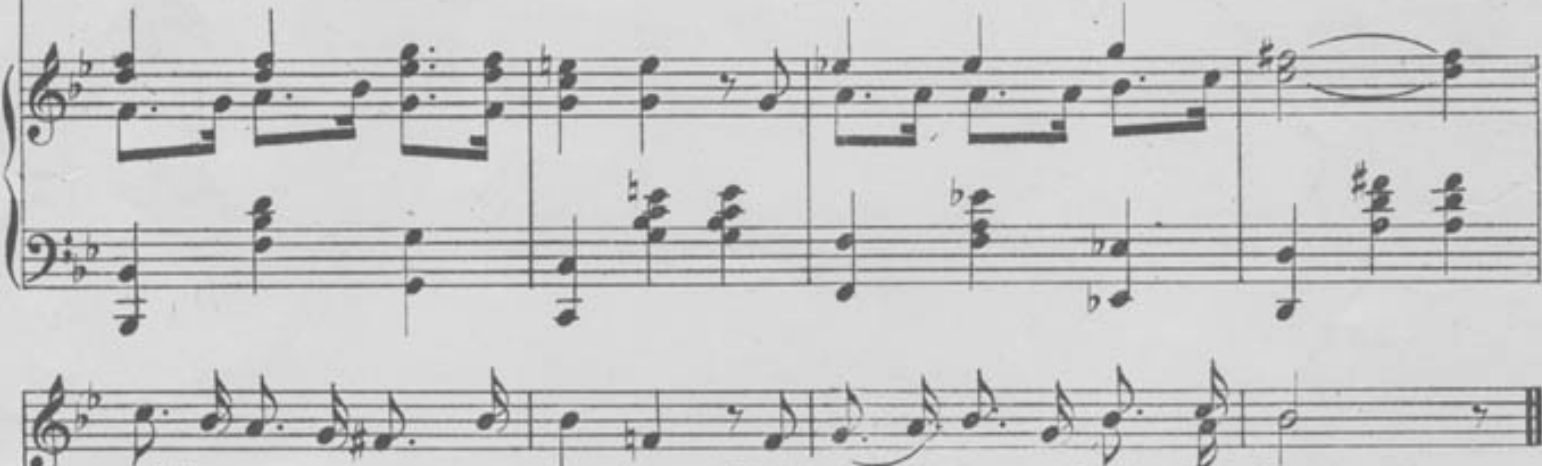

Ev'- ry cloud has sil - ver lin - ing, With old love ourheartswill bloom.

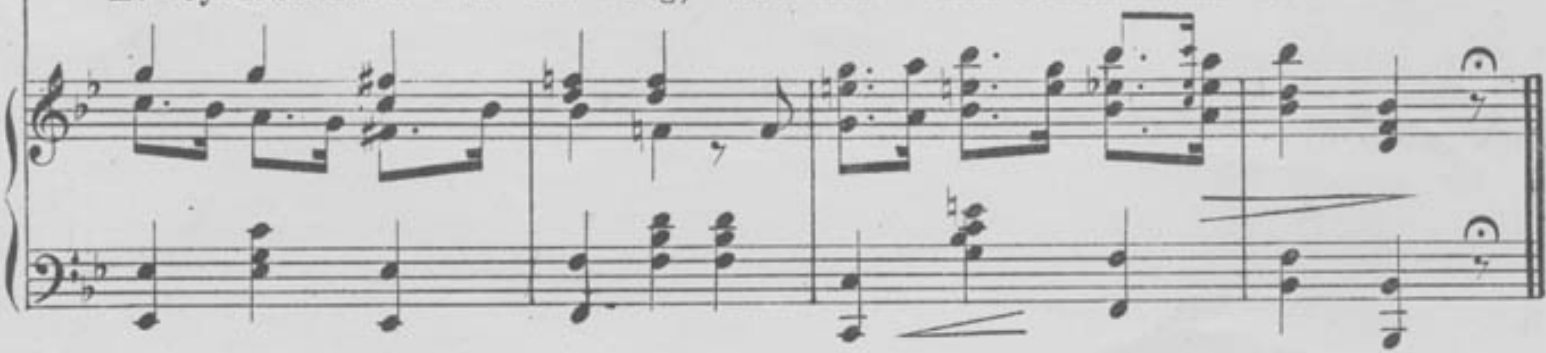

Exery cloud se. 


\section{SONG TO THE STARS.}

REVERIE NOCTURNE.

H. ENGELMANN Op. 720.

Moderato con express. м. м. во.
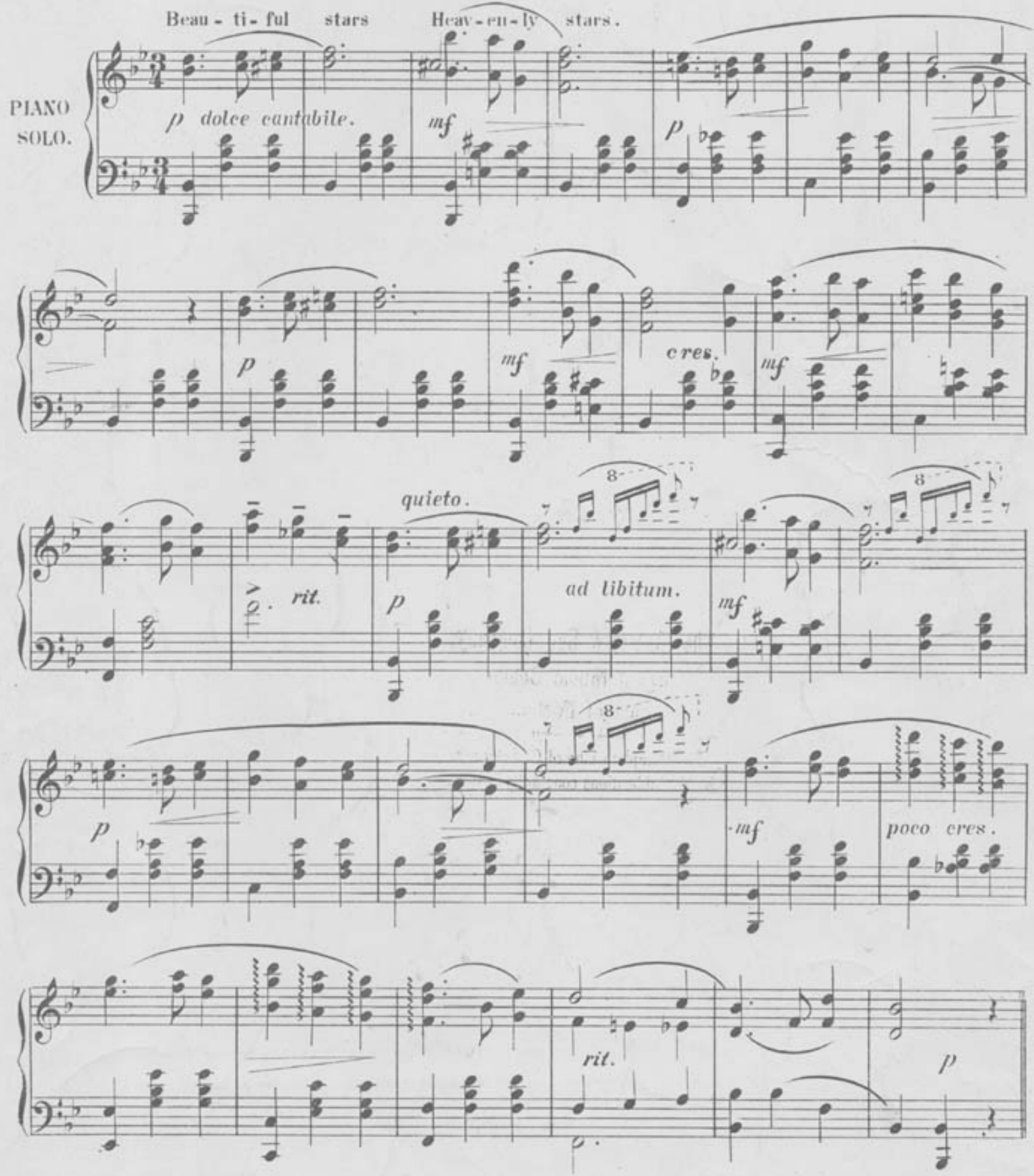

Congrizht MCMIV by Btasius und Sum.

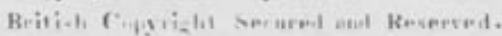

